\title{
Design of carbon nanotube field effect transistor (CNTFET) small signal model
}

\author{
Soheli Farhana \\ Malaysian Institute of Information Technology, University of Kuala Lumpur, Malaysia
}

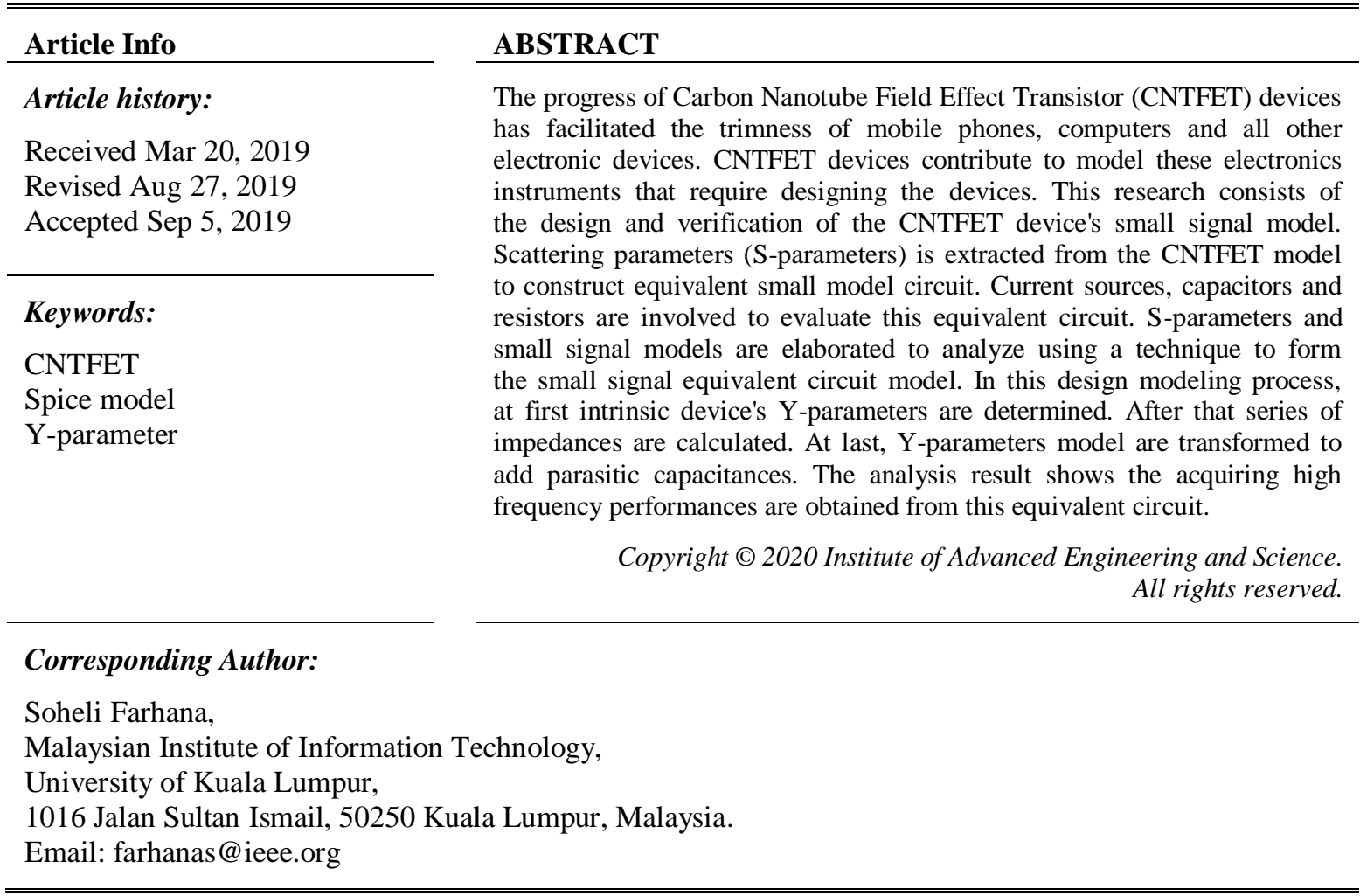

\section{INTRODUCTION}

Carbon Nanotube Field Effect Transistor (CNTFET) attracted the attention of many scientists due to its excellent electrical properties. It offers a combination of high mobility, high cutoff frequency, large current density, small size, and ballistic transport. Last four decades, the electronics device industries are occupied by silicon-based devices. Silicon-based device performance and scaling are the key point to survive them in the industries [1]. But researchers are found the scaling limitation of the silicon-based devices.

Many researchers use silicon germanium ( $\mathrm{SiGe}$ ) and CMOS technologies but the production cost is high as the surface of silicon is important due to the large number of transistor used. The development of MOS transistor has always followed the Moore's law to the use of short channel. Therefore, the physical limit of this continuous scaling is achieved, and it is necessary to search for new materials that can increase the performance of the transistors. Carbon Nanotubes (CNTs) are currently considered as promising materials of a future nano-electronics technology. CNTFETs are using CNT as channel are able to overcome the silicon-base device's limitation [2]. With the various radius of CNT contains hexagonal structure of carbon mesh. Depends on the excellent electronics structure and nanometer size of CNT, it is able to become a market potential by replacing with the silicon.

Though researchers are in early stage of CNTFET development, few of them are able to model the SPICE design, Verilog circuits [3-4]. Current transforming phenomena in CNTFET's are exhibited excellent performance due to their ON-OFF ratio characteristics. It is possible to achieve higher density of current of similar dimension by performing parallel arrangement of CNTs $[5,6]$. Some researchers are developed semiconducting CNTFET and metallic nanotubes as interconnects [7]. 
In this paper we present a simulation study of small signal model of CNTFET which act as a current amplifier that this amplifier changes an input current to a larger output current at $6.9 \mathrm{THz}$ with the low input and high output impedance is generated using CNTFET technology. C language can be used for model implementation in SPICE software for the further action. For this purpose, the CNTFET model is presented first current amplifier. We adopt a CNTFET geometry using an array of parallel nanotubes as a transistor channel in order to reduce the parasitic capacitances and to improve the high frequency performance.

\section{PHYSICS OF BALLISTIC CNTFETS}

CNTFET's ballistic assumption can be made by considering three conditions. Firstly, scattering carrier in the channel are propagating to the drain and then back to the gate without scattering. Carrier transport becomes ballistic in this situation [8]. The drain current is proportional with CNT diameter and calculated from channel length. Secondly, four capacitors are jointly recognized as CNT. Such as, gate capacitor $\left(\mathrm{C}_{\mathrm{G}}\right)$, source capacitor $\left(\mathrm{C}_{\mathrm{S}}\right)$, drain capacitor $\left(\mathrm{C}_{\mathrm{D}}\right)$ and quantum capacitor $\left(\mathrm{C}_{\mathrm{Q}}\right)$. The highest limit would be determined by $\mathrm{C}_{\mathrm{Q}}$ because of the higher value of $\mathrm{C}_{\mathrm{G}}$ than the others three capacitors [4-9]. Finally, $\mathrm{C}_{\mathrm{Q}}$ controls the CNTFET operation. If $\mathrm{C}_{\mathrm{G}}$ greater than $\mathrm{C}_{\mathrm{Q}}$ then $\mathrm{V}_{\mathrm{D}}$ increases, and channel charge decreases. Similarly, if $\mathrm{C}_{\mathrm{G}}$ less than $\mathrm{C}_{\mathrm{Q}}$ then channel charge become independent [10].

Three different structures of CNT insulator with gate are elaborated in Figure 1 and Figure 1(c) consists of the number of CNT insulator of gate which has pitch(S) in between two of them. Gate insulator is most significant due to the Current flow was prevented by the electrostatic potential barrier in the source and drain region. According to the Figure 1 (b) and (c), Gate capacitor become,

$$
C_{G}=\frac{2 \pi \varepsilon_{0} \varepsilon_{r} L}{\ln \left[2\left(t_{i n s}+r\right) / r\right]}
$$

Where, r: Nanotube radius, L: Gate length, $\varepsilon_{\mathrm{r}}$ : Dielectric constant and tins: Oxide thickness. $\mathrm{C}_{\mathrm{G}}$ becomes in the planar gate,

$$
C_{G}=\frac{2 \pi \varepsilon_{0} \varepsilon_{r} L}{\cosh ^{-1}\left(t_{i n s} / r\right)}
$$

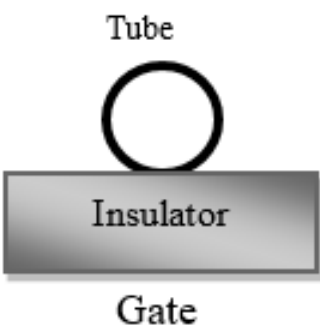

(a)

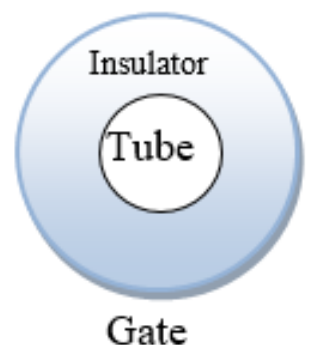

(b)

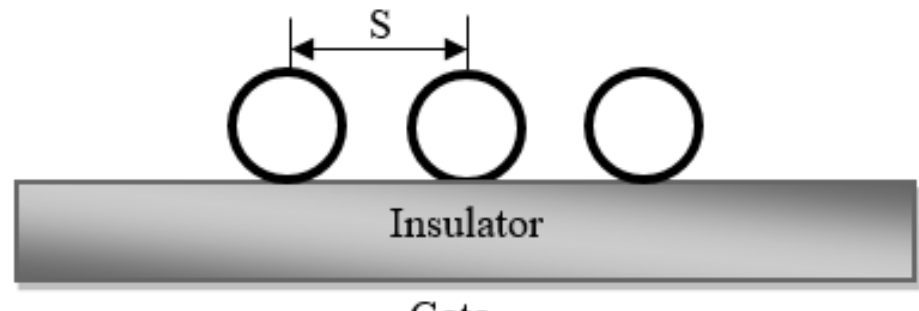

Gate

(c)

Figure 1. Different structural capacitors: (a) single CNT capacitor; (b) coaxial gated CNT capacitors; (c) array of CNT capacitors 
Figure 2 shows a 3D view of CNFET device structure that is used for the modeling in SPICE CNTFET model. It contains of Gate, Drain and Source with array of CNTs capacitors. The CNTs are embedded by gate dielectric and connected to the source and drain metals is placed on the thick oxide layers similar structure to CMOS CNT as the channel. In this paper, the proposed design of the CNTFET model configurations based on single walled carbon nanotubes (SWNTs). The periodic boundary conditions impose restrictions on available states [11-18] that depending on radius in an energy discrete set from subband structure as shown in Figure 3. An analytical calculation is assumed to illustrate the the subband's energy of semiconducting CNTs [19-29].

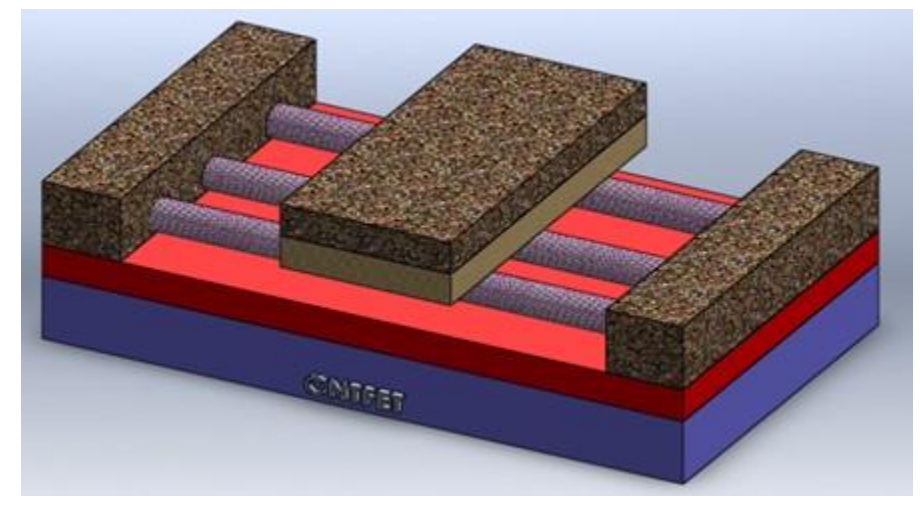

Figure 2. CNTFET 3D view of CNTFEDT model illustration

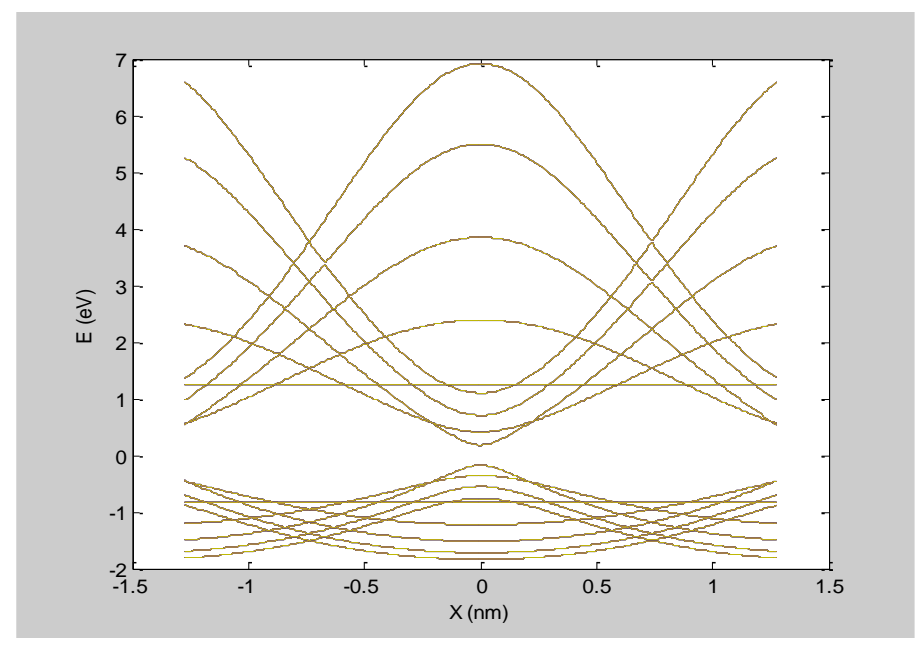

Figure 3. Single walled carbon nanotube sub-band structure

\section{SMALL SIGNAL MODELS FOR CNTFETS}

This section describes how the small signal model circuit is designed and analyzed as shown in Figure 4. Parasitic elements of this model CNTFET circuits are excluded. The intrinsic circuit of CNTFET includes inter electrode capacitance Cdg between the Drain and Gate, Gate-Source capacitance Cgs, inter electrode capacitance between the Drain and Source Cds, and gain parameter associated with the voltage controlled current source gm. Y-parameters is presented as the equivalent circuit elements. Figure 4 shows the Y-parameter representation with 3 terminals. Y12 and Y21 represent voltage controlled current sources and $\mathrm{Y} 11$ and $\mathrm{Y} 22$ represent shunt admittances.

Figure 4 also shows the CNTFET's interconnected small signal model. Due to short circuit of substrate to source, these are excluded in the small signal model. Therefore, substrate to source resistance is ignored. The entire component of the small signal model makes it scalable to fit in different dimensional device. The effective channel resistance is represented by gate resistance ( $\mathrm{Rg}$ ). In this model, Rsubd represents the bulk resistance and $\mathrm{Cjd}$ represents the bulk capacitance. 


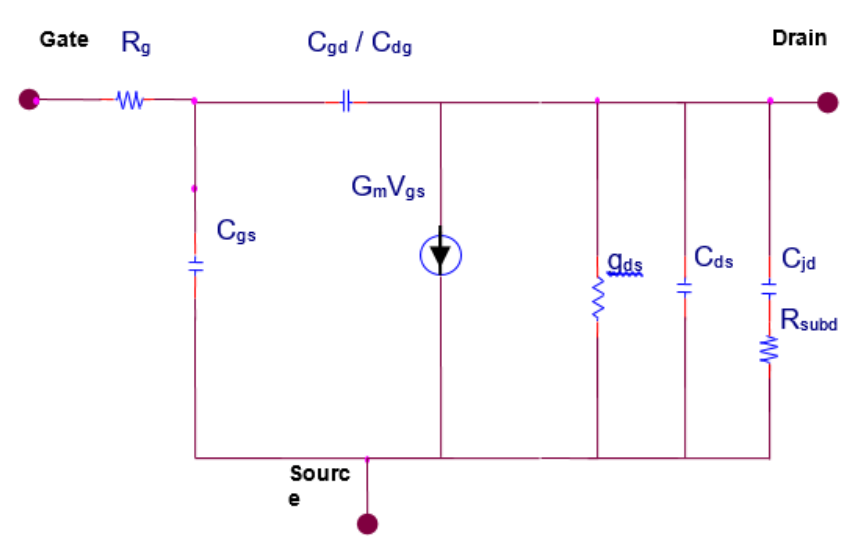

Figure 4. CNTFET small signal model

\subsection{Methodology}

The model consists of four capacitances $\mathrm{Cds}, \mathrm{Cdg}, \mathrm{Cgd}, \mathrm{Cgs}$. and three terminals source, drain and gate. Figure 3 shows the connectivity and elaboration of all the capacitors. Following analytical calculations are elucidated using drain current Id, gate current Ig and the charges,

$$
\begin{aligned}
C_{g s} & =\frac{\Delta Q_{g}}{\Delta V_{g s}}, C_{g d}=\frac{\Delta Q_{g}}{\Delta V_{g d}} \\
C_{d g} & =\frac{\Delta Q_{d}}{\Delta V_{d g}}, C_{d s}=\frac{\Delta Q_{d}}{\Delta V_{d s}} \\
i_{g} & =\frac{d Q_{g}}{d t}=\frac{f Q_{g}}{f V_{g s}} \frac{d V_{g s}}{d t}+\frac{f Q_{g}}{f V_{g d}} \frac{d V_{g d}}{d t} \\
& =C_{g s} \frac{d V_{g s}}{d t}+C_{g d} \frac{d V_{g d}}{d t} \\
i_{d} & =\frac{d Q_{d}}{d t}=\frac{f Q_{d}}{f V_{d g}} \frac{d V_{d g}}{d t}+\frac{f Q_{d}}{f V_{d s}} \frac{d V_{d s}}{d t} \\
& =C_{d g} \frac{d V_{d g}}{d t}+C_{d s} \frac{d V_{d s}}{d t}
\end{aligned}
$$

In (3) and (4), due to not equal of the capacitances Cgd and Cdg, they are expressed separately. To construct small signal mode, these capacitors are required to complete the circuit. Figure 4 shows the equivalent small signal model for CNTFET that can be charged by nonreciprocal capacitances [10]. By using linear regression method Y-parameter can be solved from the S-parameter measuring value. According to the Figure 3, Y-parameter can be elaborated in the following equations,

$$
\begin{aligned}
& Y_{11}=\frac{\omega^{2}\left(C_{g s}+C_{g d}\right)^{2} R_{g}+j \omega\left(C_{g s}+C_{g d}\right)}{1+\omega^{2}\left(C_{g s}+C_{g d}\right)^{2} R_{g}{ }^{2}} \\
& Y_{12}=\frac{-\omega^{2} C_{g d}\left(C_{g s}+C_{g d}\right)^{2} R_{g}-j \omega C_{g d}}{1+\omega^{2}\left(C_{g s}+C_{g d}\right)^{2} R_{s}{ }^{2}} \\
& Y_{21}=\frac{g_{m}-\omega^{2} C_{d g}\left(C_{g s}+C_{d g}\right)^{2} R_{g}-j \omega C_{d g}-j \omega g_{m} R_{g}\left(C_{g s}+C_{d g}\right)}{1+\omega^{2}\left(C_{g s}+C_{d g}\right)^{2} R_{g}{ }^{2}} \\
& Y_{22}=g_{m}+\frac{\omega^{2} C_{j d} R_{s u b d}+j \omega C_{j d}}{1+\omega^{2} C_{j d}{ }^{2} R_{s u b d}{ }^{2}}+j \omega C_{d s}+\frac{\omega^{2} C_{d g}{ }^{2} R_{g}+j \omega C_{d g}+j \omega^{2} R_{g}{ }^{2} C_{g s} C_{d s}\left(C_{g s}+C_{d g}\right)}{1+\omega^{2}\left(C_{g s}+C_{d g}\right)^{2} R_{g}{ }^{2}}
\end{aligned}
$$

$\omega^{2}\left(C_{g s}+C_{g d}\right)^{2} R_{g}{ }^{2}<<1$ Provides the operation frequency up to $6.9 \mathrm{THz}$. In line with this assumption, $\mathrm{Y}$-parameter can be extended to the following equations, 


$$
\begin{aligned}
& Y_{11} \cup \omega^{2}\left(C_{g s}+C_{g d}\right)^{2} R_{g}+j \omega\left(C_{g s}+C_{g d}\right) \\
& Y_{12} \cup-\omega^{2} C_{g d}\left(C_{g s}+C_{g d}\right) R_{g}-j \omega C_{g d} \\
& Y_{21} \cup g_{m}-\omega^{2} C_{d g}\left(C_{g s}+C_{d g}\right)^{2} R_{g}-j \omega C_{d g}-j \omega g_{m} R_{g}\left(C_{g s}+C_{d g}\right) \\
& Y_{22} \cup g_{d s}+\frac{\omega^{2} C_{j d}{ }^{2} R_{\text {subd }}}{1+\omega^{2} C_{j d}{ }^{2} R_{s u b d}{ }^{2}}+\omega^{2} C_{d g}{ }^{2} R_{g} \\
& +\frac{j \omega C_{j d}}{1+\omega^{2} C_{j d}^{2} R_{\text {subd }}^{2}}+j \omega C_{d s}+j \omega C_{d g}
\end{aligned}
$$

$\mathrm{g}_{\mathrm{m}}, \mathrm{g}_{\mathrm{ds}}, \mathrm{R}_{\mathrm{g}}, \mathrm{C}_{\mathrm{gd}}, \mathrm{C}_{\mathrm{dg}}, \mathrm{C}_{\mathrm{gs}}$ parameters are calculated from the following equations,

$$
\begin{aligned}
& C_{g d}=-\operatorname{Im}\left[Y_{12}\right] / \omega \\
& R_{g}=\operatorname{Re}\left[Y_{11}\right] /\left(\operatorname{Im}\left[Y_{11}\right]\right)^{2} \\
& C_{g s}=\operatorname{Im}\left[Y_{11}\right] / \omega-C_{g d} \\
& g_{m}=\left.\operatorname{Re}\left[Y_{21}\right]\right|_{\omega^{2}=0} \\
& C_{d g}=\frac{-\operatorname{Im}\left[Y_{21}\right] / \omega-g_{m} R_{c} C_{g s}}{1+g_{m} R_{g}} \\
& g_{d s}=\left.\operatorname{Re}\left[Y_{22}\right]\right|_{\omega^{2}=0}
\end{aligned}
$$

$\omega^{2} /\left[\operatorname{Re}\left[Y_{22}\right]-g_{d s}-\omega^{2} C_{d g}{ }^{2} R_{g}{ }^{2}\right]$ vs. $\omega^{2}$ use to achieve Cjd and Rsubd by the following equation.

$$
\frac{\omega^{2}}{\operatorname{Re}\left[Y_{22}\right]-g_{d s}-\omega^{2} C_{d s}{ }^{2} R_{g}}=\omega^{2} R_{\text {subd }}+\frac{1}{{C_{j d}{ }^{2} R_{\text {subd }}}}
$$

$\omega^{2} /\left[\operatorname{Re}\left[Y_{22}\right]-g_{d s}-\omega^{2} C_{d g}{ }^{2} R_{g}{ }^{2}\right]$ Helps to get Rsubd from the $\omega^{2}$ function.

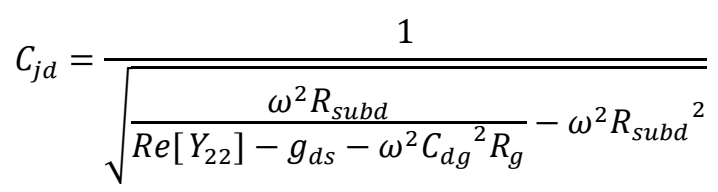

The (19) refer the calculation of $\mathrm{C}_{\mathrm{ds}}$,

$$
C_{d s}=\operatorname{Im}\left[Y_{22}\right] / \omega-C_{d g}-\frac{C_{j d}}{1+\omega^{2} C_{j d}^{2} R_{s u b d}^{2}}
$$

\section{RESULTS}

The Charge preservation parameters capacitances are examined from the (15) to (23). From the above analytical analysis, a set of simulation is done to verify the small signal model. In order to observe the performance of the CNTFET model parameters, simulation has been done for gain, gate impedance, intrinsic capacitance, transconductance, and bulk admittance with the variation of frequency. Figure 5 shows the gain versus frequency of the CNTFET small signal model. The unity gain frequency is reached at $6.9 \mathrm{THz}$ and the magnitude of current gain goes to $45 \mathrm{~dB}$. Figure 6 shows the gate impedance graph. A comparison is realized from Figure 7 in between Cgs and Cds. Finally, tranconductance and bulk admittance is plot in Figure 8. 


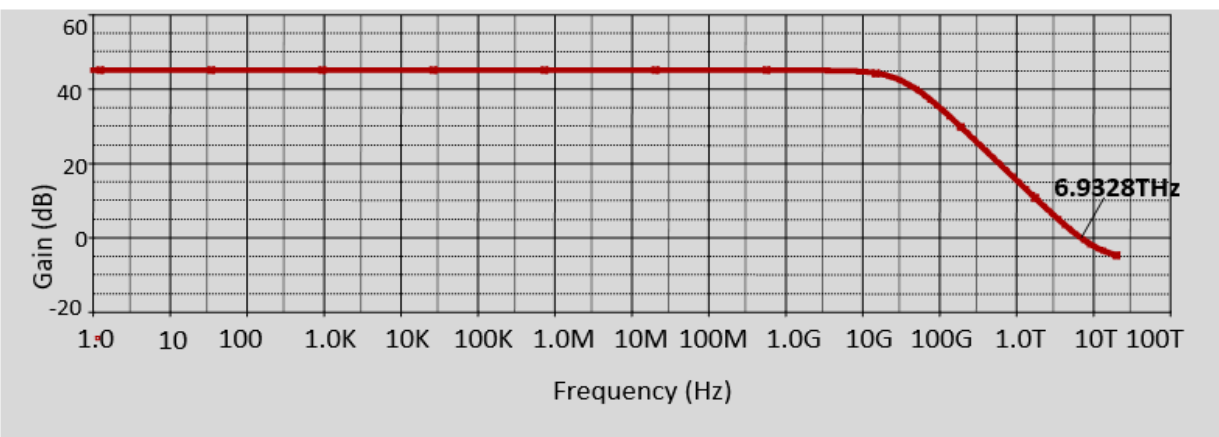

Figure 5. Output current gain of the CNTFET at 6.9 THz frequency

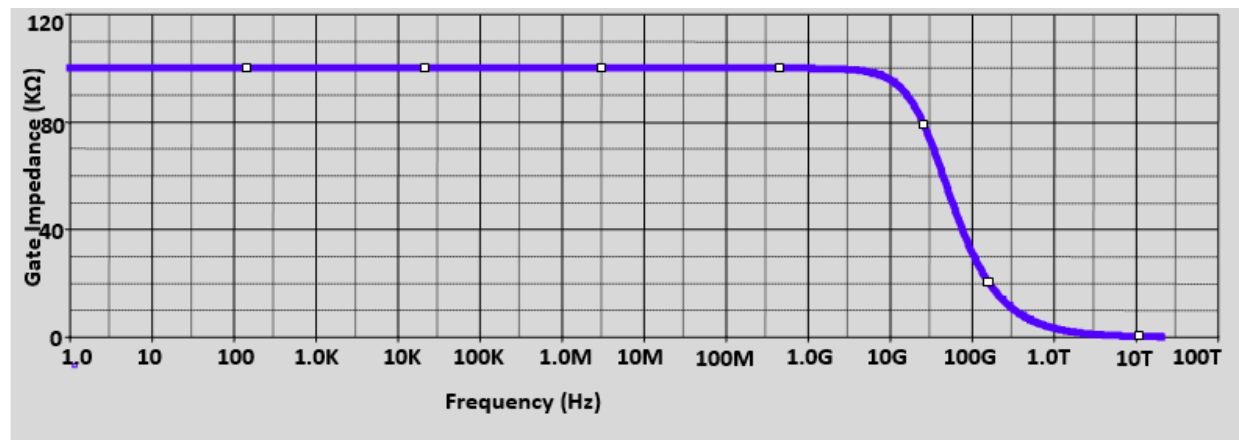

Figure 6. CNTFET Gate Impedance at high frequency

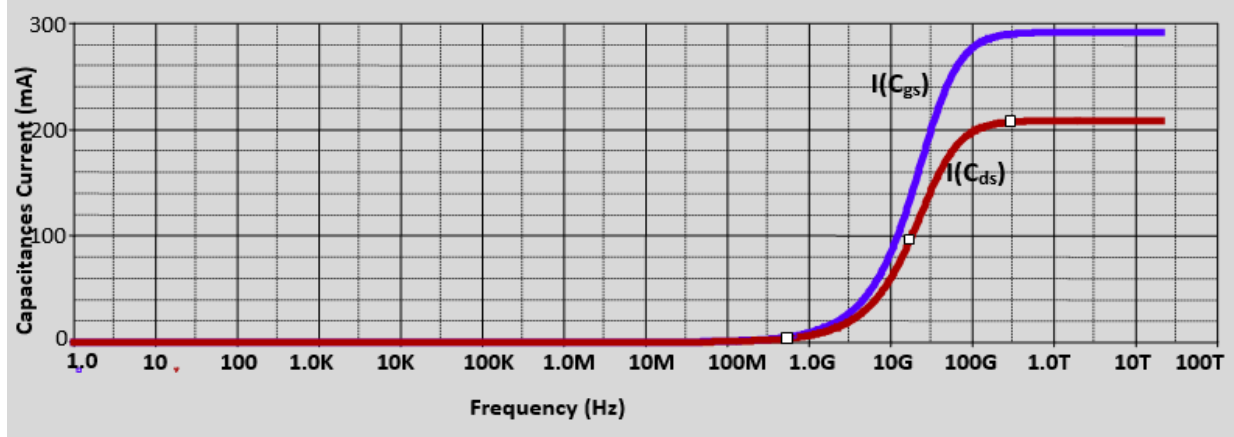

Figure 7. CNTFET's intrinsic capacitance Cgs, Cds current at $6.9 \mathrm{THz}$ frequency

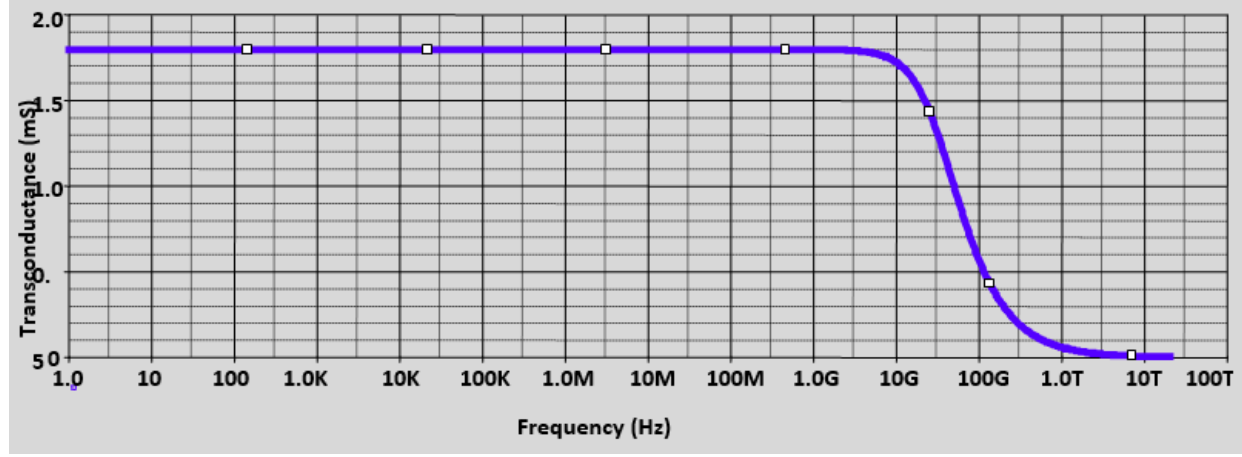

Figure 8. The transconductance (gm) of the CNTFET small signal model 


\section{CONCLUSION}

This paper elucidated a brief analysis of the proposed design of CNTFET small signal model. The design consists of proper illustration of the small signal method and demonstrated the performances by simulating small-signal parameters for CNTFET with respect to the gain of $45 \mathrm{~dB}$. The intrinsic capacitance is $14 \mathrm{aF}$, transconductance is $1.8 \mathrm{mS}$ is used in this analysis. Furthermore, this technique has introduced the capacitance to evaluate the charge preservation capacitance at the frequency of $6.9 \mathrm{THz}$.

\section{REFERENCES}

[1] G. E. Moore, "Cramming more components onto integrated circuits," Electronics, vol. 38, no. 8, pp. 114-117, Apr. 1965.

[2] P. Avouris, M. Radosavljevi'c, and S. J.Wind, "Carbon nanotube electronics and optoelectronics," in Applied Physics of Carbon Nanotubes. Germany/Heidelberg, Germany: Springer-Verlag, 2005.

[3] M. Fedawy, W. Fikry, A. Alhenawy and H. Hassan, "IV characteristics model for ballistic Single Wall Carbon Nanotube Field Effect Transistors (SW-CNTFET)," In Electronics Design, Systems and Applications (ICEDSA), 2012 IEEE International Conference on, IEEE, pp. 10-13, Nov. 2012.

[4] S. Das, S. Bhattacharya, and D. Das, "Design of digital logic circuits using carbon nanotube field effect transistors," International Journal of Soft Computing and Engineering, vol. 1, no. 6, pp. 173-178, 2011.

[5] Y.-M. Lin, J. Appenzeller, Z. Chen, Z.-G. Chen, H.-M. Cheng, and P. Avouris, "High performance dual-gate carbon nanotube FETs with 40-nm gate length," IEEE Electron Device Lett., vol. 26, no. 11, pp. 823-825, Nov. 2005

[6] G. Zhang, X. Wang, X. Li, Y. Lu, A. Javey, and H. Dai, "Carbon nanotubes: From growth, placement and assembly control to $60 \mathrm{mV} /$ decade and sub-60 mV/decade tunnel transistors," in IEDM Tech. Dig., pp. 1-4, 2006.

[7] G. F. Close and H.-S. P.Wong, "Fabrication and characterization of carbon nanotube interconnects," in IEDM Tech. Dig., pp. 203-206, 2007.

[8] K. Natori, "Ballistic metal-oxide-semiconductor field effect transistor," Appl. Phys., vol. 76, pp. 4879, 1994.

[9] A. Rahman, et al., "Theory of Ballistic Nano-transistors," IEEE Trans. on Electron Devices, vol. 50, no. 9, pp. 1853-1864, 2003.

[10] J. Guo, S. Datta, M. Lundstrom, "Assessment of silicon MOS and carbon nanotube FET performance limits using a general theory of ballistic transistors," IEDM, pp. 711-715, 2002.

[11] S. Farhana, A. Z. Alam, S. M. A. Motakabber, and S. Khan, "Analysis of CNT electronics structure to design CNTFET," In Nanoelectronics Conference (INEC), 2013 IEEE 5th International, IEEE, pp. 329-332, Jan. 2013.

[12] S. Farhana, Z. Alam, S. Motakabber, and S. Khan. "Design and Development of a Simulator for Modelling Carbon Nanotube," In IOP Conference Series: Materials Science and Engineering, vol. 53, no. 1, pp. 012049, 2013.

[13] S. Farhana, A. H. M. Alam, Sheroz Khan, and S. M. A. Motakabber. "Modeling of optimum chiral carbon nanotube using DFT," 13th IEEE Conference on Nanotechnology (IEEE-NANO), pp. 853-857, 2013

[14] S. Farhana, and A. H. M. Alam, "Environmental Friendly Device: Modeling of Carbon Nanotube with Optimum Chirality," Australian Journal of Basic \& Applied Sciences, vol. 7, no. 8, 2013.

[15] S. Farhana, A. H. M. Zahirul Alam, Sheroz Khan, and S. M. A. Motakabber, "Modeling of small band-gap CNT for designing of faster switching CNTFET," In Business Engineering and Industrial Applications Colloquium (BEIAC), 2013 IEEE, pp. 589-592, 2013.

[16] S. Farhana, A. H. M. Alam, and Sheroz Khan, "High frequency small signal modeling of CNTFET," IEEE Regional Symposium on Micro and Nanoelectronics (RSM), pp. 364-367, 2013.

[17] S. Farhana, and AHM Zahirul Alam, "Modeling of a Carbon Nanotube Sensing Device," Middle-East Journal of Scientific Research, vol. 17, no. 10, pp. 1475-1478, 2013.

[18] S. Farhana, A. H. M. Alam, Sheroz Khan, and S. M. A. Motakabber, "Investigation on carbon nanotube electronics structure," Pensee, vol. 75, no. 11, pp. 123-129, 2013.

[19] P. Avouris, M. Freitag, V. Perebeinos, "Carbon-nanotube photonics and optoelectronics," Nature photonics, vol. 2, no. 6, pp. 341, 2008.

[20] X. Cui, M. Freitag, R. Martel, L. Brus, P. Avouris, "Controlling energy-level alignments at carbon nanotube/Au contacts," Nano Letters, vol. 3, no. 6, pp. 783-7, Jun. 2003.

[21] S. Datta, M. Radosavljevic, B. Doyle, J. Kavalieros, J. Brask, A. Majumdar, R.S.Chau, "inventors; Intel Corp, assignee," Carbon nanotube energy well (CNEW) field effect transistor, United States patent US 7,170,120, Jan. 2007.

[22] M.M. Shulaker, G. Hills, N. Patil, H. Wei, H.Y. Chen, H.S. Wong, and S. Mitra, "Carbon nanotube computer," Nature, vol. 501, no. 7468, pp. 526-530, Sep. 2013.

[23] E. Pop, "Energy dissipation and transport in nanoscale devices," Nano Research, vol. 3, no. 3, pp. 147-69, 2010.

[24] G.J. Brady, A.J. Way, N.S. Safron, H.T. Evensen, P. Gopalan, M.S. Arnold, "Quasi-ballistic carbon nanotube array transistors with current density exceeding Si and GaAs," Science advances, vol. 2, no. 9, Sep. 2016.

[25] A. Todri-Sanial, R. Ramos, H. Okuno, J. Dijon, A. Dhavamani, M. Widlicenus, K. Lilienthal, B. Uhlig, T. Sadi, V. Georgiev, A. Asenov, "A survey of carbon nanotube interconnects for energy efficient integrated circuits," IEEE Circuits and Systems Magazine, vol. 17, no. 2, pp. 47-62, May 2017.

[26] F. Yang, X. Wang, J. Si, X. Zhao, K. Qi, C. Jin, Z. Zhang, M. Li, D. Zhang, J. Yang, Z. Zhang. "Water-assisted preparation of high-purity semiconducting $(14,4)$ carbon nanotubes," ACS nano, vol. 11, no. 1, pp. 186-93, 2016. 
[27] L. Aspitarte, D. McCulley, A. Bertoni, J. Island, M. Ostermann, M. Rontani, G. Steele, and E. Minot, "Giant modulation of the electronic band gap of carbon nanotubes by dielectric screening," Scientific reports, vol. 7, no. 1, pp. 8828, Aug. 2017.

[28] F. Sharifi, M. Moaiyeri, K. Navi, N. Bagherzadeh, "Robust and energy-efficient carbon nanotube FET-based MVL gates: A novel design approach," Microelectronics Journal, vol. 46, pp. 12, pp. 1333-42, Dec. 2015.

[29] Graf A, Tropf L, Zakharko Y, Zaumseil J, Gather MC, "Near-infrared exciton-polaritons in strongly coupled singlewalled carbon nanotube microcavities," Nature communications, vol. 7, pp. 13078, Oct. 2016.

\section{BIOGRAPHY OF AUTHOR}

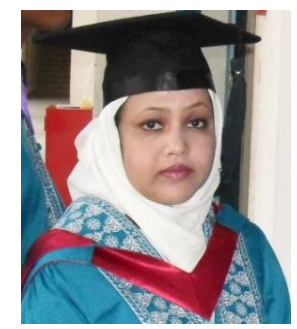

Dr. Soheli Farhana joined University of Kuala Lumpur, Malaysia in December 2018. She received her $\mathrm{PhD}$ in Electrical Engineering from the International Islamic University Malaysia in 2016. Dr. Farhana was the Visiting Scholar at MIT, MA, USA in 2017. Dr. Farhana's research focuses on the Carbon Nanotube Field Effect Transistor and Nano-biosensor. Dr. Farhana received the IIUM Faculty of Engineering Best doctoral dissertation award at $32^{\text {nd }}$ IIUM Convocation in 2016, IIUM president award, Gold medal from international research exhibition, IIUM post-doctoral fellowship in 2016 and the best paper award at the engineering congress at imperial college, United Kingdom. She was also the recipient of the Professional of the Year Award from Worldwide Who's Who in 2018. 